\title{
Do the Meaning of Work and the Coherence between a Person and His Work Environment Express the Same Reality?
}

\author{
Samuel Nyock Ilouga ${ }^{1}$, Aude Carine Moussa Mouloungui², Caroline Arnoux-Nicolas ${ }^{3}$, \\ Jean Luc Bernaud ${ }^{3}$ \\ ${ }^{1}$ Université de Yaoundé 1, Douala, Cameroon \\ ${ }^{2}$ Université Omar Bongo, Libreville, Gabon \\ ${ }^{3}$ CNAM de Paris, Paris, France \\ Email: nyock.ilouga@gmail.com
}

How to cite this paper: Ilouga, S. N., Mouloungui, A. C. M., Arnoux-Nicolas, C., \& Bernaud, J. L. (2018). Do the Meaning of Work and the Coherence between a Person and His Work Environment Express the Same Reality? Psychology, 9, 2175-2193. https://doi.org/10.4236/psych.2018.98124

Received: July 3, 2018

Accepted: August 20, 2018

Published: August 23, 2018

Copyright $\odot 2018$ by authors and Scientific Research Publishing Inc. This work is licensed under the Creative Commons Attribution International License (CC BY 4.0).

http://creativecommons.org/licenses/by/4.0/

\begin{abstract}
The international literature review on the meaning of work reveals that, there is still an epistemological confusion between the meaning and coherence constructs. To date, no research has empirically proven that the meaning of work, which emerges from the perception of the work (Gomez-Gonzalez et al., 2013), its purpose (Proulx et al., 2013) and its contribution to the meaning of existence (Hackman \& Oldman, 1976, Rosso et al., 2010 and Steger et al., 2012), has an autonomous and a distinctive character not only with respect to the perceived and effective coherence existing between the worker and the working environment, but also vis-à-vis other factors which view the meaning as a subset of more important constructs like psychological empowerment. To address this gap, this research aims at continuing the empirical validation on the inventory of the meaning of work (Arnoux-Nicolas et al., 2016) while examining not only its factorial structure, but also and especially the conceptual and empirical differences between the meaning and coherence. Confirmatory factor analyses were carried out on 623 hospital staffs in Cameroon, showing that the two-dimensional structure of the meaning inventory presents better statistical indices of adequacy on the real data and accounts for $71.486 \%$ of the explained variance. Correlational analyses that were carried out on 359 samples validated the distinctive and autonomous character of meaning with respect to coherence $(r \approx-32)$.
\end{abstract}

\section{Keywords}

Meaning of Work, Person-Environment Fit, Social Entropy 


\section{Introduction}

Long reserved for philosophical reflection because of its elusive and inoperative character (Arnoux-Nicolas, Sauvet, Lhotellier, \& Bernaud, 2016), the concept of meaning has recently entered the psychology field of work and the number of research that is devoted to it is growing sustainably (Harpaz, Honig, \& Coetsier, 2002; Morin, 2008; Rosso, Dekas, \& Wrzesniewski, 2010; Steger, Dik, \& Duffy, 2012). This research is primarily aimed at examining the relationship between individuals and their living environment, given the significant encounters of their socio-professional experiences (MOW International Research Team, 1987). On the other hand, as analysed by existential psychotherapists, meaning essentially refers to life on earth and participates in the cosmogonic order of reason to be or live (Frankl, 2009). Parallel to this approach, Sartre (1946) and Camus (1942) suggest the invention of a meaning and the full investment of oneself in its accomplishment, rather than feeling sorry for the fate of man who finds himself in search of meaning in a world that lacks it. Applied to the context of companies, meaning refers to work and in so doing, does not fundamentally depart from its existential philosophical understanding, since professional reflection is considered in a life course taken as a whole (Bernaud, 2015). However, if it is acknowledged that he who no longer finds meaning in his life is doomed (Frankl, 1969), what happens to him who finds no meaning in his work? It is in this regard that Compte-Sponville (2014), opposing meaning to the value of things, particularly observes that the meaning of work necessarily refers to something other than the actual work. This, he says, makes sense only in proportion to the value attributed to it. The construction of the said meaning results from at least three sources of different interpretations: meaning, direction, and sensation. Curiously, research on the meaning of work first and foremost explores the meaning of the work (Brief \& Nord, 1990; MOW International Research Team, 1987; Super \& Sverko; 1995; Spreitzer et al., 1997; Wrzesniewski, Dutton, \& Debebe, 2001; Arnoux-Nicolas et al., 2016) and the contents attributed to the meaning of work in all of these research works do not always coincide exactly. It seems that the diversity of the study contexts is at the origin of this variability (Oishi, Diener, Lucas, \& Suh, 1999). So what is the content taken by the meaning of work in an entropic context, marked by emptiness, dissipation, pauperism, and which do transform workers into hired men ready to sell their services to the highest bidder? In such a context, does the meaning of work, viewed as a dimension of the meaning of life (Bernaud et al., 2015), differ from the coherence borrowed from Yalom (1980) and Morin (2008)?

From the scientific stand point, the proliferation of concepts and empirical redundancy are problematic and run counter to the parsimony principle by Le, Schmidt, Harter, \& Lauver, 2010. It becomes essential to determine whether the meaning of work is different from the other constructs to which it seems related. This research carries investigations to continue the empirical validation of the Meaning of Work Inventory (IST) by clarifying its distinctiveness with respect to 
coherence. This is to confirm the factorial structure of the meaning of work inventory proposed by Arnoux-Nicolas et al. (2016) and verify the specificity of the construct in relation to coherence.

\section{Theoretical Framework}

\subsection{Context}

The study of the meaning of work is presented with a new acuteness for workers who are employed in an entropic context, marked by the collapse of the value given to work (Mercure \& Vultur, 2010), with as corollaries boredom, dissipation, emptiness, apathy and dishonest conducts. These conducts are the opposite of the so-called enabling behaviors (Boudrias \& Savoie, 2006) and could reflect a lack of inventive intelligence that allows employees to take initiatives that go beyond prescriptions, especially when they are deficient or contradictory (Dejours, 1998). Social entropy is the unpleasant situation in which Cameroonian workers find themselves because of the corruption of the agents and the principles which underlie informal work and which constitute with it emerging entities, originating from the chaotic functioning of the Cameroonian social system, markers of social entropy. The interpretation of entropy as a "measure of disorder” has several proponents (Carnap, 1966; Muller \& Weiss, 2005). This interpretation is not entirely irrelevant to thermodynamic entropy (Jodouin, 2015) In fact, considering the interpretation inspired by the second principle of thermodynamics according to which entropy is a measure of the loss of work (Carnot, 1824), and given the Promethean conception of work as what allows the establishment and stability of social order (Smith, 1991), it is not forbidden to establish a correspondence between high entropy and disorder. This random operation took over the administrations and companies of the national territory where it abolished all the principles of management and favored the emergence of a clandestine organization. In such an environment, employees become hired men who are exclusively inclined to sell their services to the highest bidder. When work thus becomes an opportunity to engage in a traffic that is organized around it, it becomes urgent to wonder about the meaning of real work without which the traffic it generated is no longer possible. If, as Spreitzer (1995) asserts, the meaning of work is one of the four cognitions that make up empowerment, it is not absurd to be interested in meaning if we wish to restore a little humanism into work. This idea had already been expressed by May, Gilson, \& Harter (2004). The aim of this research is to propose a meaning-based approach (Rifkin, 1996; Frankl, 1969; Yalom, 1980) to reconstruct the intelligence of work. In the specific context of this research, it is all about testing the factorial structure of the inventory of the meaning of the work of Arnoux-Nicolas et al. (2016) and checking whether the meaning evaluated by this tool corresponds to the meaning found in the work through the coherence between the importance given to certain attributes of work and their actual presence at the workplace (Morin, 2008). 


\subsection{The Meaning of Work}

Referring to Sartre (Yalom, 1980), work can hardly be placed under activities that could give meaning to life. These activities, he says, are fair, good, self-satisfied and do not require other sources of motivation. But Compte-Sponville (2010) adds that work is not a moral value and therefore cannot be self-sufficient since it is essentially a means to serve extra-professional roles. He says it is for this reason that it makes sense. But since meaning is a fundamentally extrinsic notion, the meaning of work is rooted in roles that an individual fulfills in other spheres of life.

This paradox testifies to the complexity of the concept of meaning, and justifies the abundance and diversity of approaches that are dedicated to it (Bernaud, 2015). Among the remarkable contributions to understanding the meaning of work, it should be noted with Kant (1993, 1st edition in 1975) and Sartre (1996) the idea that the meaning is the result of a permanent construction or quest in a world which is devoid. This conquest refers to experiences from different life paths. The idea supported by Jung that the human being completes the work of creation and "imprints his mark of perfection" revitalizes the Promethean conception of work and makes it a creative activity (Méda \& Vandramin, 2013). When it allows to get values such as empathy, altruism or generativity are used, work becomes a key vector of meaning (Adler, 1951). The construction of this meaning would result from the sense of coherence between the worker's values and behavior. The idea that the meaning of work can be viewed from the perspective of coherence has many followers (Yalom, 1980; Morin, 2008). More than ever, this orientation requires the scholarly articulation between the different spheres of life and requires conciliations and regulations between values (Lourel \& St-Onge, 2012). Similar to life, work is not a new concern (Bernaud, 2015). And, like life, the concept of work did not appear spontaneously, endowed with all its attributes since its ancient origins (Méda \& Vandramin, 2013). The different meanings it has nowadays have been added together over time. However, we can remember that work is an energy expenditure through a set of activities aimed at producing something useful (Firth, 1948; Fryer \& Payne, 1984; Shepherdson, 1984). It is fundamentally facing with the test that conditions the development of ingenuity to cope with (Dejours, 1998). It can be pleasant or unpleasant, and it acquires its meaning through its insertion in exchanges of economic and social nature. People work for the sake of themselves and their families. Even the pleasure that good work can bring has, at first, the effect of widening the narcissistic foundations of its author and therefore increasing self-esteem. It is for love of oneself that we love good work. Hence the search for coherence between oneself and what one does. By projecting into a work well done, one admires one's own qualities and one appreciates one's intrinsic talent. It is also the same operation when we admire other people's work. In doing so, we compare ourselves to them and recognize them as alter ego, endowed with the same qualities, triumphing over the same difficulties and overcome the same 
obstacles. The study by Arnoux-Nicolas et al. (2016) selected three theoretical approaches to develop a tool to measure the meaning of work: the approach based on the understanding of work (Gomez-Gonzalez, Leger, Bourdages, \& Dionne, 2013), the approach based on the orientation of work (Proulx et al., 2013) and the approach relied on the contribution of work for the construction of the meaning of life (Hackman \& Oldham, 1976; Rosso et al., 2010; and Steger et al., 2012). The authors have shown that the inventory of the meaning of work thus elaborated is made up of four culturally sensitive sub-measures namely: the importance of work, the understanding of work, the direction of work and the purpose of work. The set revealed an adequate adjustment to the data collected from a sample of French workers. In this research, the verification of the data adequacy of this factor structure of the inventory of the meaning of the work constitutes a preliminary step before being able to examine the possible redundancy with the coherence indices.

Hypothesis $\left(H_{1}\right)$ : The factorial structure of the sense inventory, made up of four sub-measures, will satisfactorily fit the data. However, the distribution of items within the dimensions may deviate from the original model given the contextual contingencies.

\subsection{Meaning and Coherence}

In psychology, meaning refers essentially to the experience of coherence (Yalom, 1980; Morin \& Cherré 2001), cohesion, balance, and even fullness (Csikszentmihalyi, 2003). Meaning is also associated with vocation (Frankl, 1969) and resides in the adequacy between the current situation and the deepest aspirations. The meaning of the work could be obtained through the correspondence between the ideal work representation and the characteristics of the current work (Arronsson, Bejerot, \& Härenstam, 1999). Thus, the meaning of work can be conceived as an effect of coherence between the subject and the work he performs, the degree of harmony or balance he achieves in his relationship with work (Csikszentmihalyi, 2003). In this perspective, the concept of coherence is related to that of consistency (Heider, 1946) or congruence (Osgood \& Tannenbaum, 1955) according to which the ideas one has about something tend to organize in balance systems and, therefore, any inconsistency leads to (intellectual, emotional, behavioral, etc.) activities in order to re-establish the balance. However, the postulate that the coherence found in the work corresponds to the meaning of the work is based on a theoretical reasoning that derives from existential psychology (Yalom, 1980). Frankl (2009) states that the fundamental requirement of man is the completeness of meaning, which fulfills at least three functions: it directs the attitudes and behaviors of a person; it confronts the person through the trials and his lifetime, in order to force him to fulfill his destiny; it finally enables the understanding of the existence and integration of the personality. The coherence that the subject finds in his relation to work gives him a feeling of psychological security and serenity that will help him to face the trials 
that inevitably entails the very exercise of his functions Without this integration, it is very difficult for an individual to have a history that is intelligible and a goal in life that is logically associated with this story. Through a phenomenological approach, Morin \& Cherré (2001) define the meaning as a coherence effect between the characteristics that individuals look for in their work (valued characteristics of work) and those they perceive in their current work (current characteristics of work). From measurements of presence and importance, Morin \& Cherré (2001) identified indices of coherence for six aspects of work (utility, ethics, personal efficiency, conditions for success, work pleasure, personal safety) and consider these indices of coherence as tools for measuring the meaning of work. An issue having little coherence for all these indices would necessarily find less meaning in his work than an individual who would perceive more coherence for each of these indices. These observations of Morin \& Cherré (2001) primarily rely on a measurement of the valued characteristics of work that is comparable to other structures based on values and meaning of work (MOW International Research Team, 1987; Super \& Sverko, 1995). These indices are equally used as independent variables within the regression models. For example Morin \& Cherré (2001) demonstrate that the coherence indices of personal safety predict part of people's anxiety as well as their irritability. However, no research has empirically demonstrated so far that it is valid to consider the coherence between a person and his environment as an element corresponding to the meaning found in his work. Moreover, the second objective of our work is to check whether the indexes of coherence which are calculated from the valued and present characteristics measurements of the work constitute a measure of the meaning of work and would be very highly bound to the dimensions of IST $(r>.70)$.

Hypothesis $\left(H_{2}\right)$ : The dimensions of the sense inventory have a distinct character and will not be redundant with the indices of consistency (i.e. $r>.70$ ).

\section{Methodology}

Two periods were necessary to carry out research so as to test our hypothesis. Initially, the objective was to validate the factorial structure of the sense inventory while the objective of the second was to assess the possible redundancy between the dimensions of the meaning of work and the indices of coherence, via the evaluation of correlations.

\subsection{Samples}

Although the crisis of meaning tends to spread to all sectors of activity (Yalom 1980), the health workers seem to be more exposed to the loss of meaning because of the permanent confrontation with death. In Cameroon, it is estimated that $80 \%$ of patients with serious conditions die in the hospital for lack of money and care (Akua Agyepong, et al., 2017). We therefore logically chose to target this population to conduct this study. Several directorates of hospitals in the Littoral region (Cameroon) provided us with computerized lists of medical staff 
with a total of 300 doctors and 500 nurses. We invited all 800 employees to participate in the survey. To achieve this, we were present during sectoral meetings organized by the hospitals' services. We insisted on the fact that the supervision authorities accepted the implementation of the research with the care personnel, after validating the ethical guarantee provided by the ethics committee of the Yaoundé 1 University. But they are not implicated in the research however. Our sample is made up of volunteers and wise people who have agreed to submit their completed questionnaire. The administration of the questionnaire took place between 20 July 2017 and 10 January 2018. A total of 623 employees agreed to answer the questionnaire, which corresponds to a response rate of $77.87 \%$. Among these respondents, $67.4 \%$ are women and $32.6 \%$ are men. The age of the respondents ranges from 21 to 62 years old, then the average is 44.4 years old (standard deviation equal to 9.08 years). Our sample includes $40.02 \%$ of nurses, $11.11 \%$ of caregivers, $16.11 \%$ of laboratory engineers and technicians; $19.75 \%$ of hospital majors, and $13.01 \%$ of doctors. To meet the methodological requirements of the confirmatory analysis procedure, our sample has been divided into two parts. The comparison tests revealed homogeneity between the two samples from the point of view of the age $(\mathrm{t}=1.111 ; p>.26)$, of the $\operatorname{sex}\left(\chi^{2}=1.20 ; p>.45\right)$ and of the distribution in the different socio-professional categories $\left(\chi^{2}=1.67 ; p>.23\right)$.

The first sample (s1), made up of 264 hospital employees, and completed the inventory of the meaning of work by Arnoux-Nicolas et al. (2016). This will help test the stability of the factorial structure of the meaning inventory, which is hypothesis 1 , with a statistical power estimated from the classical adequacy indices (TLI $\geq .90$; CFI $\geq .90$ and RMSEA $\leq .05$, Kim, 2005). The second sample (s2), on the other hand, consists of 359 workers who completed all the variables under study (the inventory of meaning and the two measures of importance and presence of the characteristics of Morin's et al. work (2001). This second sample will make it possible to check the links between the measures of the meaning and the coherence indices, that is to test the hypothesis 2 , with an adequate statistical power ( $\mathrm{r} \geq .70, p<.05$; Cohen, 1992).

\subsection{Instruments}

The survey was conducted using a self-administered questionnaire. The questionnaire was distributed to participants with a postage-paid envelope addressed to the research team, and bearing the words research questionnaire on the meaning of work. This questionnaire has three parts. The first part deals with the meaning of work. The second part evaluates the presence of some characteristics of work and the importance given to them (MOW International Research Team, 1987; Morin \& Cherré, 2001). The third part deals with the participant's information. For each of these scales, the respondents had to agree, estimate the frequency or indicate the degree of importance by positioning themselves on a 4-point Likert scale ( 1 = strongly disagree, 4 = quite agree).

We used the inventory of meaning proposed by Arnoux-Nicolas et al. (2016). The 17 statements that compose it make it possible to describe the usefulness of 
work, the meaning of work in general, the place it occupies in the people's life and the factors that help in making sense of it. In accordance with the approach developed by McGartland-Rubio et al. we formed a group of fifteen experts comprised of medical students and hospital interns. The experts' work consisted in evaluating the representativeness of each item with regards to the definition used for the connecting dimension; to appreciate the clarity of the words and the level of language used to facilitate the understanding of the items by all participants; to evaluate the comprehensiveness of the composition of each dimension and possibly propose new items; to reduce the items from their original cultural load (McGartland-Rubio, Berg-Weger, Tebb, Lee, \& Rauch, 2003). Specifically, the experts had to evaluate each item on a Likert-type scale with four response levels [ex. $1=$ (not clear at all), to $4=$ (quite clear)]. The spaces were left at the disposal of the experts to suggest new questions or to reformulate available items. At the end of the in-depth examination of the validity, the representativeness and the clarity of the wording of the statements, 8 items were reformulated $(2,3,4,9,10,12,14,16)$, none were deleted, several items (ex: $1,2,5,8,16,17)$ were transferred from one dimension to another and the overall structure of the scale was reorganized. This preliminary study required discussions with the authors of the scale until satisfactory formulation was obtained. Moreover, the IST was confronted with competing scales. We chose to use the six items proposed by May et al. (2004) to evaluate the sub-measure of meaning in the psychological empowerment scale (Spreitzer, 1995) and the job satisfaction scale (JSS) of Fouquereau and Rioux (2002). Example: I realize that my work helps discover new things. Both tools were used to test the convergent validity of the IST. The internal consistency indexes of these scales were satisfactory for the continuation of our study (Cronbach's $\alpha=.94$ for IST and .95 for measurement proposed by May et al. (2004) and .96 for JSS).

We used a revised version of the measure of the importance and the presence of certain characteristics of the work proposed by the Crievat research group (Fournier et al., 2016) and resulting from the work of MOW International Research Team (1987). This tool has 50 items divided into 6 valued characteristics of work (usefulness of work, pleasure, autonomy, work ethic, interpersonal relationship and recognition). Example: That matches with my skills. The internal consistency of this measure is evaluated at .89 for the measure of presence and .91 for the measure of significance.

The third part has to do with personal information. This section is made up of two subsections. The first subsection deals with personal information (age, sex, level of education, number of significant changes in the past year, psychological distress indices, psychological well-being indices, etc.) and the second subsection deals with current employment (type of organization, size of organization, type of job, number of years of service, etc.).

\subsection{The Indexes of Coherence}

The approach chosen by Morin to measure the meaning found in work fits into 
the field of research commonly called "theory of work adjustment" which includes, among other things, the studies done on P-E fit (Chatman, 1989; Rounds et al., 1987; NyockIlouga, 2010). In this type of study, we consider the level of adjustment (coherence) between the characteristics of an individual (personality's feature or skills) and those of his environment (tasks, roles, etc.) to predict the quality of his subsequent behaviors and attitudes in the workplace. However, some researchers, more concerned with methodological and statistical aspects, have shown that there are problems with these indices (Cronbach, 1987; Edwards, 1994; Evans 1991).

Edwards $(1993,1994)$ showed that the ambiguity of this type of measurement lies in particular in the calculation of the indices of coherence and the interpretation of the results obtained. An indice of coherence can be calculated from two measures (e.g. the current salary and the desired salary). This is a bivariate coherence indice. The main calculations used for the creation of such indices are the algebraic difference (result of simple subtraction between the scores obtained from the two measures) the absolute difference (subtraction result expressed in positive value), the product of the two underlying variables and the square of the difference (the square of the result of the subtraction) (Edwards, 1994).

The second approach used to obtain a coherence indice is that one in which the index is obtained from two measures containing more than one dimension per measure (e.g. the personality of an individual and the personality required for a job). This method corresponds to that used by Morin \& Cherré (2001). It is then a coherence indice on the similarity of the profiles. The main calculations used to create such coherence indices are the sum of the absolute differences, the sum of the squares of the differences and the correlation between profiles (Edwards, 1994). None of these methods are perfect since they are both focused on the variables rather than individuals to sift out individual profiles based on the degree of consistency. In addition, each of them poses problems whose risk of multicollinearity is the most important. Multicollinearity refers to a very high level of cross-correlation between independent variables in a regression equation. It is a serious problem when one wants to examine the effects specific to each of the independent variables taken separately in a regression model (Haccoun, 1996). By using either of the above mentioned methods of calculation, often times the coherence index correlates strongly with one of the measurements from which it is derived. In so doing, the coherence indice has little or no value in reducing multicollinearity, rather it is recommended to create coherence indexes from the product of the underlying measures (Cronbach, 1987). For this study, we chose to use the coherence indices calculated from the absolute difference, the square of the difference and the product of the underlying measures (Edwards, 1994).

\subsection{Statistical Analysis}

To verify hypothesis 1 concerning the structure of the inventory of meaning, confirmatory factor analyses (CFA) were preferred. We used different test indic- 
es of adjustment of the proposed models. In general, an irrelevant chi-square corresponds to a perfect fit to the data. This indicator is very sensitive to the size of the sample. For this reason we have associated other relative adjustment indexes. Thus, values of CFI (comparative fit indice) and NNFI (TLI) (non-normed fit indice) and AIC (Akaike comparative indice) will be used. Acceptance standards vary according to authors. Some suggest a validation threshold at 90 (Merdsker, Williams, \& Holahan, 1994), others are more demanding in setting the threshold beyond .95 (Hu \& Bentler, 1999). We also considered that RMSEA and SRMR values below 06 indicate a very good fit (Schermelleh-Engel, Moosbrugger, \& Müller, 2003). Finally, to determine which of the models should be selected, we used the difference of chi-square $\left(\Delta \chi^{2}\right)$. In addition, the AIC indice which simultaneously integrates the degree of fit of the models and their number of degrees of freedom to estimate the most parsimonious model was also used (Byrne, 2009). For the AIC indice, we selected the model with the lowest value (Kline, 2011). On the other hand, in order to verify hypothesis 2, correlational analyses are performed between the indices of coherence and the dimensions of the meaning of the work. It should be noted that preliminary analyses (e.g. descriptive statistics) helped to ensure that the basic postulates of the previous analyses were respected (normality of distributions, multicollinearity, missing data, and extreme scores).

\section{Findings}

\subsection{The Factor Structure of the Spirit of Hard Work Inventory}

In the first instance, we carried out exploratory analyzes focusing on the method of extraction known as major axes with oblique rotation, as recommended by Steger et al. (2012). Four dimensions were got from these analyzes carried out on a sample of 264 subjects. However, this factor structure in four dimensions, based on the theoretical model Arnoux-Nicolas et al. (2016) with different distribution of the items within the factors, proved to be unstable notably because it included a dimension (negative valence of the work) containing less than three items and presented statistical irregularities enabling to suspect a bad adequacy to the sampling: a high value of the determinant of the correlation matrix ( $\Delta=$ $\left.1.561{ }^{\star} 10^{2}\right)$ and a rather modest internal consistency $(\alpha=.71)$. We have opted to a two-dimensional structure including 15 of the 17 initially identified and which presents better statistical indicators: the Kaiser-Meyer-Olkin indice $=.94$; the determinant of the correlation matrix $\Delta=.066$; internal consistency index $\alpha$ $=.95$ and Bartlett's sphericity test $\chi_{126}^{2}=4212.819 ; p<.001$. Both dimensions account for $71.486 \%$ of the explained variance. This two-factor solution seems parsimonious since the percentage of residual values greater than .05 stabilized at $22 \%$ in the reconstituted matrix (Byrne, 2009). Table 1 below shows the distribution of items and their saturation with each of the two dimensions. The first dimension is made up of 7 items which relationship with the underlying variables vary between .807 and .895 . Contributions from items 14 and 15 
Table 1. Sample presentation.

\begin{tabular}{ccc}
\hline Sex & Men & Women \\
& $32.6 \%$ & $67.4 \%$ \\
Mean age (standard deviation) & \multicolumn{2}{c}{-4.4 (9.04) } \\
Occupation & Percentage (\%) \\
Doctors & 13.01 \\
Nurses & 40.02 \\
Caregivers & 11.11 \\
Laboratory engineers and technicians & 16.11 \\
Hospital majors & 19.75 \\
\hline
\end{tabular}

were considered insufficient to be retained in the analysis. They have been removed. The composition of this dimension educes the social utility of work. The second dimension is composed of eight statements that refer to the misinterpretation of the purpose of the work. Saturations within this dimension vary from 735 to 848 . The average value of Cronbach $\alpha$ for the entire items is equal to 95 .

\subsection{Confirmatory Analysis}

The second part of the sample (359) allowed the comparison of the three factorial structures: $\boldsymbol{M}_{1}$ (the theoretical model proposed by Arnoux-Nicolas et al. (2016)), $\boldsymbol{M}_{\mathbf{3}}$ (the four-factor model inspired by the theoretical model but of which distribution of items within the dimensions differs from the theoretical model and) $\boldsymbol{M}_{2}$ (the two-dimensional model). The results completely reject the hypothesis $H_{1}$. The data in Table 2 show that the two-dimensional model provides a better fit to the data $(\mathrm{CFI}=.94 ; \mathrm{TLI}=.93$; $\mathrm{SRMR}=.06$; $\mathrm{RMSEA}=.04)$.

\subsection{Convergent Validity}

The intra-factor variance is estimated on average at .86\% indicating excellent internal convergence (Kline, 2011). However, Table 3 shows that the correlations between the measurement of Arnoux-Nicolas et al. (2016) and the two other measures selected for this study are certainly significant, but their values are often negative and remain modest $\left(\mathrm{r}=-.32^{\star}\right.$ with the May scale, $\mathrm{r}=-.40^{\star}$ with the professional satisfactory scale of Fouquereau and Rioux, 2002). The results show that these are different scales that probably do not measure the same reality Nevertheless, a significant and very strong positive correlation was found between Fouquereau's ESP and Rioux and the measurement of meaning from May's psychological empowerment scale $(\mathrm{r}=.85)$. The value of this correlation coefficient is much greater than the threshold of .70 which is reached when the constructs are redundant. In view of these results, we were forced to carry out two complementary tests to ensure that: 1) IST measures well the meaning of the work among Cameroonian medical staff. For this, we used the $\rho_{v c}$ of Jöreskog, more adapted than the Cronbach $\alpha$ for confirmatory analyzes; 2 ) that the IST 
Table 2. Factorial structure in two-dimension of IST.

\begin{tabular}{|c|c|c|}
\hline \multirow{2}{*}{ ITEMS } & \multicolumn{2}{|c|}{ Component } \\
\hline & 1 & 2 \\
\hline Generally speaking, my job means allot for me & .895 & -.142 \\
\hline In my life, I attach allot of considerations for my job & .888 & -.161 \\
\hline In my job, it is stimulating to achieve the goals & .866 & .036 \\
\hline My current job offers opportunities to gain much admiration from the society & .854 & -.201 \\
\hline I realize that my work helps discover new things & .851 & -.093 \\
\hline My work has a clear and specific directions & .842 & -.116 \\
\hline I have clearly understood the usefulness of my work & .807 & -.234 \\
\hline I don't clearly see the meaning of my current work & -.146 & 848 \\
\hline I don't really understand how contributive my work is & -.260 & .822 \\
\hline I sometimes think my work is not very useful & -.109 & .813 \\
\hline I don't understand what effect my work has on the society & -.222 & .782 \\
\hline My job doesn't help me have truly clear life prospects & -.129 & .766 \\
\hline My work does not contribute much in my life & -.100 & .751 \\
\hline I often wonder if at my job position, I do really know what are actually the goals & .009 . & 743. \\
\hline I frequently don't understand the purpose of my work & -.039 & .737 \\
\hline
\end{tabular}

Table 3. Validation of the two-dimensional structure of the IST Sample $1 . \mathrm{N}=264 ;{ }^{* *} p$ $<.001$.

\begin{tabular}{ccccccccccc}
\hline & $\chi_{(d l)}^{2}$ & $\chi^{2} / d l$ & CFI & TLI & SRMR & RMSEA & RMSEA IC 90\% & AIC & $\Delta \chi^{2} / d l$ \\
\hline$M_{1}$ & $1071.917_{(84)}^{* * *}$ & 12.761 & 696 & 619 & 459 & 181 & $.17-.19$ & 1319.916 & \\
$M_{2}$ & $322.31_{(89)}^{* * *}$ & 3.621 & 94 & 93 & $(0639)$ & $(045)$ & $.35-.65$ & 535.865 & \\
$M_{3}$ & $795.758_{98}$ & 8.12 & $(827)$ & $(798)$ & $(332)$ & $(14)$. & $.13-.15$ & 1057.535 & - \\
\hline
\end{tabular}

a model $M_{2}$ consisting of two sub-measures (Work Incomprehension (1) and Social Utility of Work (2)) seems to offer better fitting indices to actual data.

produces different results from the other constructs. That's why, we used the difference of $\chi^{2}$ between constrained models to test the discriminant validity. Both tests are conform to the procedure recommended by Kline (2011). The value of the $\rho$ for the 15 items selected in this study is .75 , indicating that the explained variance shared by the 15 items is sufficiently high to confirm that the STI remains a measure of the meaning of the work in the Cameroon hospital context. The discriminant validity test was also conclusive since $\Delta \chi_{30}^{2}=138.78$; $p<.001$. It seems that the IST does not share its field of action either with the three terms proposed by May (2004), nor with the ESP of Fouquereau \& Rioux (2002) (see Table 4). In addition, the dimensions of Arnoux-Nicolas's (2016) inventory of meaning maintain an opposite relationship expressed by a negative and significant value of the correlation coefficient observed between them $(\mathrm{r}=$ -.48). It seems that for the workers interviewed during this study, the under 
Table 4. Averages, standard deviations and correlations for the different scales of the meaning of work: ST1 (Understanding of work_IST); ST2 (Usefulness of Work_IST); SG (Scale of May's Meaning of Work, 2004); ESP (Satisfaction Scale of Fouquereau and Rioux, 2002), ${ }^{* *} p<.001 ;{ }^{* *} p<.01 ;{ }^{\star} p<.05$.

\begin{tabular}{lcccccc}
\hline & Avr & E-T & 1. & 2. & 3. & 4. \\
\hline 1) ST1 & 1.72 & .6 & & & \\
2) ST2 & 3.32 & .48. & $-.48^{* *}$ & & \\
3) SG (May) & 4.74 & .72 & $-.36^{*}$ & $(30)$. & \\
4) ESP & 4.04 & .74. & $-.38^{*}$ & $(33)$. & $.85^{* * *}$ & \\
\hline
\end{tabular}

standing of the work, which includes its orientation and a significant part of its meaning, seems to call into question the usefulness of the work. This incompatibility between the understanding and the usefulness of the work raises many questions since it occurs in a hospital environment where behavioral biases seem to multiply (Nguimfack, 2016) in defiance of ethical values. The reality of the work within the medical staff seems, at the very least, confusing.

\subsection{Link between Indexes of Coherence and the Meaning of Work}

Verification of the presence of the common variance bias is a prerequisite suggested by Podsakoff et al. (2003) for the estimation of linear links between two reputedly redundant constructs. This condition was assessed using the Harman test which states that: when this bias exists in the tested measures, a single factor would emerge from the exploratory factor analysis or, where the factor structure comprises more than one factor, the first would total more than $65 \%$ of the explained variance, reflecting the size effect. In this study, both conditions were satisfactory since the factorial structure of the Arnoux-Nicolas et al. (2016) has two dimensions, the first of which accounts for only $39 \%$ of the variance explained, and the measurement of the importance of work attributes revealed a factor structure composed of 6 factors, the first of which accounts for $26 \%$ of the variance. This six-factor structure was imposed to the measure of presence to facilitate the computation of the indexes of coherence. These observations allow the testing of Hypothesis 2 through the examination of correlations between the meaning inventory data and the indexes of coherence resulting from measures of importance and presence of certain characteristics of the work (see Table 5).

Generally, if we stick to the constraint set by Podsakoff et al. (2003) that the linear relationship between two constructs must result in a correlation coefficient greater than .65 to conclude that the two constructs produce redundant information, we are obliged to find that the coherence, measured by the absolute difference, the square of the difference as well as the product between the importance and the presence of work characteristics relative to the six dimensions of the Morin \& Cherré (2001) scale do not correspond to the meaning of the work. The values of the correlation coefficients did not reach thresholds that would cast doubt on the distinctiveness of the STI and its contribution in 
Table 5. Correlation between IST and the coherence indices NOTES: d_E (algebraic differential between importance and presence regarding ethic); d_U (algebraic differential between importance and presence regarding social utility); d_A (algebraic differential between importance and presence regarding autonomy); d_Rela (algebraic differential between importance and presence regarding relationship); d_Recon (algebraic differential between importance and presence regarding recognition); $E_{I} \times E_{P}=$ product between importance and presence of ethical dimension; $U_{I} \times U_{P}=$ product between importance and presence of social utility dimension; $A_{I} \times A_{P}=$ product between importance and presence of autonomy dimension; $R E L_{I} \times R E L_{P}=$ product between importance and presence of relationship dimension; $\mathrm{REC}_{\mathrm{I}} \times \mathrm{REC}_{\mathrm{P}} \mathrm{ESP}=$ product between importance and presence of recognition dimension; $\mathrm{Pl}_{\mathrm{I}} \times \mathrm{Pl}_{\mathrm{P}}=$ product between importance and presence of pleasure dimension; ESP refers to the professional satisfaction scales of Fournier (2002). ${ }^{* *} p<.01 ;{ }^{*} p<.05$.

\begin{tabular}{|c|c|c|c|c|c|c|c|c|c|c|}
\hline & Id-EI & $\left(\mathrm{d} \_E\right)^{2}$ & Id_UI & $\left(\mathrm{d} \_\mathrm{U}\right)^{2}$ & Id_AI & $\left(\mathrm{d} \_A\right)^{2}$ & Id_RelaI & $(\text { d_Rela })^{2}$ & Id_ReconI & $(\text { d_Recon })^{2}$ \\
\hline ST1 & -.10 & -.07 & -.03 & -.01 & -.12 & -.12 & -.10 & -.11 & -.02 & -.03 \\
\hline ST2 & .15 & .13 & -.04 & .03 & .07 & .09 & .00 & .01 & -.07 & -.02 \\
\hline SENS TOTAL & .01 & .02 & $-.22^{*}$ & $-.26^{*}$ & $.21^{*}$ & -.05 & -.12 & -.10 & -.09 & -.08 \\
\hline SENS May & -.13 & -.06 & $.21^{\star}$ & $.25^{\star}$ & .16 & .17 & -.05 & .01 & -.15 & -.11 \\
\hline \multirow[t]{2}{*}{ ESP } & -.12 & -.06 & $.25^{*}$ & $.31^{\star *}$ & $-.21^{*}$ & $-.25^{*}$ & -.17 & -.09 & -.19 & -.15 \\
\hline & ID_PII & \multicolumn{2}{|c|}{$\left(\mathrm{D} \_\mathrm{Pl}\right)^{2}$} & $\mathrm{Pl}_{1} \times \mathrm{Pl}_{2}$ & $\mathrm{E}_{\mathrm{I}} \times \mathrm{E}_{\mathrm{P}}$ & $\mathrm{U}_{\mathrm{I}} \times \mathrm{U}_{\mathrm{P}}$ & $\mathrm{A}_{\mathrm{I}} \times \mathrm{A}_{\mathrm{P}}$ & \multicolumn{2}{|c|}{$\mathrm{REL}_{\mathrm{I}} \times \mathrm{REL}_{\mathrm{P}}$} & $\mathrm{REC}_{\mathrm{I}} \times \mathrm{REC}_{\mathrm{P}}$ \\
\hline ST1 & -.07 & \multicolumn{2}{|c|}{-.08} & $-.30^{*}$ & -.22 & -.21 & -.15 & \multicolumn{2}{|c|}{-.20} & -.19 \\
\hline ST2 & .07 & \multicolumn{2}{|c|}{.08} & .02 & -.05 & -.00 & -.13 & \multicolumn{2}{|c|}{-.16} & .04 \\
\hline SENS TOTAL & -.24 & \multicolumn{2}{|c|}{-.24} & $-.29^{*}$ & $-.28^{*}$ & -.23 & $-.28^{*}$ & \multicolumn{2}{|c|}{$-.31^{*}$} & -.16 \\
\hline SENS May & -.14 & \multicolumn{2}{|c|}{-.05} & $.26^{*}$ & .22 & $.30^{*}$ & .08 & \multicolumn{2}{|c|}{.20} & $.45^{\star *}$ \\
\hline ESP & -.03 & \multicolumn{2}{|c|}{.08} & $.26^{*}$ & .19 & $.29^{*}$ & .24 & \multicolumn{2}{|c|}{$.30^{*}$} & $.47^{* *}$ \\
\hline
\end{tabular}

assessing the meaning of the work. Indeed, only the correlation coefficients obtained between the coherence indexes calculated on the ethical dimensions $(\mathrm{r}=$ $\left.-.28^{\star}\right)$, pleasure $(-.31)$, social utility $\left(r=-.23^{\star}\right)$, autonomy $\left(r=.28^{\star}\right)$, relationship $\left(r=-.31^{\star}\right)$ and the meaning inventory of Arnoux-Nicolas et al. (2016) have proven to be significant. These same dimensions are also correlated, in inversely equivalent proportions, with the scale of the meaning of May et al. (2004). These results tend to show that the gap between the expectations of social utility, pleasure, workplace support, and the reality of work in these respective aspects causes loss of meaning at work. On the other hand, when workers become autonomous consistent with their expectations, they consider that their work makes sense. However, the observed values of correlation coefficients give us the strong impression that, at least in its mathematical version, constitutes an alternate reality of the meaning of the work. It confirms the Hypothesis $H_{2}$ of our research. Similar results were obtained by Denis \& Morin (2003) in a research conducted with hospital personnel in Canada.

\section{Discussion}

We initiated this study in order to demonstrate that the meaning of the work that emerges from the workers' understanding of their work (Gomez-Gonzalez et al., 2013), the purpose of work (Proulx et al., 2013), as well as its contribution 
in the drafting of the meaning of life (Hackman \& Oldman, 1976; Rosso et al., 2010 and Steger et al., 2012), has an independent and distinctive character not only in relation to perceived and real coherence between the worker and his work environment, but also vis-à-vis other phenomenon which consider the meaning as a subset of a more important construct (psychological empowerment). Pursuing that objective; we examined the inventory factor structure of the meaning of work proposed by Arnoux-Nicolas et al. (2016). Our approach has led us to look into matters concerning medical personnel so as to carry out these investigations over serious dysfunctions that have become markers of national social entropy. The issue of the meaning of work and, that of the meaning of life meet a special resonance. Our results show that the averages recorded on the evaluation of different aspects of the meaning of work are close to the theoretical average of the Likert scale to 4-point (2.5). We carry out investigations with the medical personnel who are the subject of many criticisms relating to the diversion and the commercialization of medical treatments, but also the poor quality of care for the sick. Such an observation may reflect a mistrust of the workers vis-à-vis the researchers who are also suspected of having preconceptions and contributing to the controversy. Confirmatory factor analyzes revealed that the two-dimensional factor structure (the social utility of work, 7 items and the lack of understanding the work, 8) fits the data better than the four-dimensional theoretical model. negative links $(r=-.48)$ found between the two dimensions of the meaning of the work require their simultaneous use so as to define the total reality covered by the construct since the two sub-measures are not redundant. However, the opposition between the understanding of work and its social utility raises ethical questions that are permanent in a hospitable context. Can one construe that the dysfunctions that characterize the real work of the nursing staff force them to break the ethical rules of their profession? This ethical conflict is not without consequences on the psychological health of the medical staff who moreover do not benefit from any psychotherapeutic support so as to analyze the crisis situations and to facilitate the mobilization of the coping mechanisms.

The IST revealed its autonomy not only in relation to the meaning of the work considered as a dimension of psychological empowerment (Spreitzer, 1995; Boudrias and Savoie, 2006), but also in relation to Fouquereau's job satisfaction scale, Rioux (2011). Statistical analyzes revealed intra-constructed proximity and inter-constructed distance, thus validating internal convergence and external differentiation. It should be noted that our results provide only a mitigated support to those obtained by the authors of the IST (Arnoux-Nicolas et al., 2016) who reported a four-dimensional structure as well as positive and significant correlations between the dimensions of IST and the scale of professional satisfaction. These comments disagree with the hypothesis. $H_{1}$ although it is recognized that the need for meaning is a universal reality, the cultural rooting of its construction urges to be cautious when comparing the results obtained from different populations. Efforts must therefore be intensified to result in a scale of the meaning of the work enabling to identify not only all the dimensions of 
meaning (meaning and sensation included) but also to strengthen its distinctive nature compared to coherence. In this regard, our findings deviate from the conceptual argumentation which presumes a theoretical proximity between meaning and coherence (Yalom, 1980; Morin, 2008). In doing so, they corroborate the hypothesis $\mathrm{H}_{2}$ and support the distinctive nature of the meaning of work in relation to the person-environment coherence. In this context, the use of STI should be favored by organizations wishing to adopt support programs on the meaning in favor of people's development. To that end, the identification of individuals profiles based on the degree of perceived coherence could have added value.

\section{Conclusion}

The study of the meaning of work remains relevant in contexts where it appears to be lacking despite the appearances, and the medical personnel met within the framework of this study knows the meaning of their work through its social utility and efforts to understand the reality that does not currently yield expected results. The recurrent malfunctioning makes the reality of the practice of medicine incomprehensible and generates ethical biases which themselves can also find a solution through accompanying programs in the sense (Bernaud, Lhotellier, Sovet, Arnoux-Nicolas, \& Pelayo, 2015). In an environment where workers are enjoined to think about their job and where nature is responsible of organizing cooperation between men, workers are looking for understanding and clarification of roles and responsibilities. However, the heterogeneity of our sample is an obstacle to the stability of the IST revealed structure.

\section{Conflicts of Interest}

The authors declare no conflicts of interest regarding the publication of this paper.

\section{References}

Adler, A. (1951). Le sens de la vie. Paris: Payot.

Akua Agyepong, I., Sewankambo, N., Binangwaho, A., Coll-Seck, A. M., Corrah, T., Ezeh, A., \& Piot, P. (2017). The Path to Longer and Healthier Lives for All Africans by 2030: The Lancet Commission on the Future of Health in Sub-Saharian Africa. The Lancet, 390, 2803-2859. https://doi.org/10.1016/S0140-6736(17)31509-X

Arnoux-Nicolas, C., Sauvet, L., Lhotellier, L., \& Bernaud, J.-L. (2016). Development and Validation of the Meaning of Work Inventory among French Workers. International Journal of Education and Vocational Guidance, 17, 165-185.

Arronsson, G., Bejerot, E., \& Härenstam, A. (1999). Healthy Work: Ideal and Reality among Public and Private Employed Academics in Sweden. Public Personnel Management, 28, 197-215. https://doi.org/10.1177/009102609902800203

Bernaud, J.-L. (2015). Le "sens de la vie" comme paradigme de conseil en orientation. Psychologie Française, 61-72.

Bernaud, J.-L., Lhotellier, L., Sovet, L., Arnoux-Nicolas, C., \& Pelayo, F. (2015). 
Psychologie de l'accompagnement: Concepts et outils pour développer "le sens" de la vie et du travail. Paris: Dunod. https://doi.org/10.3917/dunod.berna.2015.01

Boudrias, J.-S., \& Savoie, A. (2006). Les manifestations comportementales de l'habilitation au travail: Développement d'un cadre conceptuel et d'un instrument de mesure. Psychologie du Travail et des Organisations, 12, 119-138. https://doi.org/10.1016/j.pto.2006.03.005

Brief, A. P., \& Nord, W. R. (1990). Meaning of Occupational Work. Toronto: Lexington Books.

Byrne, B. M. (2009). Structural Equation Modeling with AMOS: Basic Concepts, Applications, and Programming (2nd Ed.). Mahwah, NJ: Lawrence Erlbaum.

Camus, A. (1942). L'Etranger. Paris: Gallimard.

Carnap, R. (1966). Philosophical Foundations of Physics. New York: Basic Books.

Carnot, S. (1824). Réflexions sur la puissance motrice du feu et sur les machines propres à développer cette puissance. Paris: Gauthier-Villard.

Chatman, J. A. (1989). Improve Interactional Organizational Research: A Model of Person-Organizational Fit. Academic of Management Review, 14, 333-349.

Cohen, J. (1992). A Power Primer. Psychological Bulletin, 112, 155-159.

Compte-Sponville, A. (2014). Petit traité des grandes vertues. Paris: Point.

Cronbach, L. J. (1987). Statistical Test for Moderator Variables: Flaws in Analyses Recently Proposed. Psychological Bulletin, 102, 414-417.

https://doi.org/10.1037/0033-2909.102.3.414

Csikszentmihalyi, M. (2003). Flow: The Psychology of Optimal Experience. New York: Harper and Row.

Dejours, C. (1998). Souffrance en France. Paris: Seuil.

Denis, J. F., \& Morin, E. M. (2003). Meaning of Work: Validation of a 6-Factor Structure Measuring the Valued Working Characteristics.

Edwards, J. R. (1994). The Study of Congruence in Organizational Behaviour Research: Critique and a Proposed Alternative. Organizational Behaviour and Human Decision Processes, 58, 51-100. https://doi.org/10.1006/obhd.1994.1029

Evans, M. G. (1991). The Problem of Analysing Multiplicative Composites: Interaction Revisited. American Psychologist, 46, 6-15.

Firth, R. (1948). Anthropological Background to Work. Occupational Psychology, 22, 94-102.

Fouquereau, E., \& Rioux, L. (2002). Development of the French-Language Professional Life Satisfaction Scale: An Exploratory Study. Canadian Journal of Behavioural Science, 34, 210-215. https://doi.org/10.1037/h0087173

Fournier, G., Poirel, E., \& Lachance, L. (2016). Éducation et vie au travail, Tome 2: Perspectives contemporaines sur les parcours de vie professionnelle (pp. 29-63). Québec: Presses de l'Université Laval.

Frankl, V. E. (1969). The Will to Meaning. New York, NY: New American Library.

Frankl, V. (2009). Nos raisons de vivre. À l'école du sens de la vie. Paris: InterEdition/Dunod.

Fryer, D., \& Payne, R. (1984). Working Definitions. Quality of Working Life, 1, 13-15.

Gomez-Gonzalez, S. A., Leger, D., Bourdages, L., \& Dionne, H. (2013). Sens et projet de vie. Québec: Presse de l’Université du Québec. 
Haccoun, P. R. (1996). Manuel Pédagique sur les analyses multivériées. Uniuversité de Montréal.

Hackman, J. R., \& Oldham, G. R. (1976) Motivation through the Design of Work: Test of a Theory. Organizational Behavior and Human Performance, 16, 250-279. https://doi.org/10.1016/0030-5073(76)90016-7

Harpaz, I., Honig, B., \& Coetsier, P. (2002). A Cross-Cultural Longitudinal Analysis of the Meaning of Work and the Socialization Process of Career Starters. Journal of World Business, 37, 230-244. https://doi.org/10.1016/S1090-9516(02)00090-1

Heider, F. (1946). Attitudes and Cognitive Organization. Journal of Psychology, 21, 107-112.

Hu, L., \& Bentler, P. (1999). Cutoff Criteria for Fit Indices in Covariance Structure Analysis: Conventional Criteria versus New Alternatives. Structural Equation Modeling, 6, 1-55. https://doi.org/10.1080/10705519909540118

Jodouin, L. (2015). Emergence et entropie: Une analyse critique des stratégie emergentistes basées sur le concept d'entropie. Paris: UniversitéPanthéon-Sorbonne.

Kant, E. (1993). Fondements de la métaphysique des mours. Paris: Grasset, le livre de poche.

Kline, R. B. (2011). Principles and Practice of Structural Equation Modeling (3rd ed.). New York, NY: Guilford Press.

Le, H., Schmidt, F. L., Harter, J. K., \& Lauver, K. J. (2010). The Problem of Empirical Redundancy of Constructs in Organizational Research: An Empirical Investigation. Organizational Behavior and Human Decision.

Lourel, M., \& St-Onge, S. (2012). Du conflit à l'enrichissement travail-travail: Résultats et perspectives de recherche. Psychologie du Travail et des Organisations, 18, 100-101.

May, D. R., Gilson, R. L., \& Harter, L. M. (2004). The Psychological Conditions of Meaningfulness, Safety and Availability and the Engagement of the Human Spirit at Work. Journal of Occupational and Organizational Psychology, 77, 11-37. https://doi.org/10.1348/096317904322915892

McGartland-Rubio, D., Berg-Weger, M., Tebb, S. S., Lee, S. E., \& Rauch, S. (2003). Objectifying Content Validity: Conducting a Content Validity in Social Work Research. Social Research, 27, 94-104.

Méda, D., \& Vendramin, P. (2013). Réinventer le travail: Une histoire de la valeur accordée au sens du travail. Paris. France: Presses Universitaires de France.

Mercure, D., \& Vultur, M. (2010). La signification du travail: Nouveau modele productif et ethos du travail au Québec. Québec: Presse de l’Université Laval.

Merdsker, G., Williams, I., \& Holahan, P. (1994). A Review of Current Practices for Evaluating Causal Models in Organizational Behavior and Human Resources Management Research. Journal of Management, 45, 322-335.

Morin, E. M., \& Cherré, B. (2001). Les cadres face au sens du travail. Revue Française de Gestion, 126, 83-93.

Morin, E. M. (2008). Meaning of Work, Mental Health, and Organizational Involvement. Montreal: IRSST.

MOW International Research Team (1987). The Meaning of Working. New York, NY: Academic Press.

Muller, I., \& Weiss, W. (2005). Entropy and Energy. Heidelberg: Springer Verlag.

Nguimfack, L., \& Ndje Ndje, M. (2016). Appréhender la dynamique éthique des soins et biais comportementaux dans la pratique médicale: une approche qualitative. Ethique et 
Santé, 13, No. 1.

NyockIlouga, S. (2010). La convergence dans les organisations: Effet sur la satisfaction et l'engament au travail. Berlin: EUE.

Oishi, S., Diener, E., Lucas, R. E., \& Suh, E. M. (1999). Cross-Cultural Variations in Predictors of Life Satisfaction: Perspectives from Needs and Values. Personality and Social Psychologie Bulletin, 25, 980-990. https://doi.org/10.1177/01461672992511006

Osgood, C. E., \& Tannenbaum, P. H. (1955). The Principle of Congruity in the Prediction of Attitude Change. Psychological Review, 62, 42-55. https://doi.org/10.1037/h0048153

Podsakoff, P. M., MacKenzie, S. B., Lee, J. Y., \&Podsakoff, N. P. (2003). Common Method Biases in Behavioral Research: A Critical Review of the Literature and Recommended Remedies. Journal of Applied Psychology, 88, 879-903. https://doi.org/10.1037/0021-9010.88.5.879

Proulx, T., Markman, K. D., \& Lindberg, M. J. (2013). Introduction: The New Science of Meaning. In K. D. Markman, T. Proulx, \& J. Lindberg (Eds.), The Psychology of Meaning (pp. 3-14). Washington DC: American Psychological Association.

https://doi.org/10.1037/14040-001

Rifkin, J. (1996). La fin du travail. Paris: La découverte.

Rosso, B. D., Dekas, K. H., \& Wrzesniewski, A. (2010). On the Meaning of Work: A Theoretical Integration and Review. Research in Organizational Behavior, 30, 91-127. https://doi.org/10.1016/j.riob.2010.09.001

Rounds, J. B., Dawis, R. W., \& Lofquist, L. H. (1987). Measurement of Person-Environment Fit and Prediction of Satisfaction in the Theory of Adjustment. Journal of Vocational Behavior, 31, 297-318.

Sartre, J. P. (1996). L'existentialisme est un humanisme. Paris: Folio.

Schermelleh-Engel, K., Moosbrugger, H., \& Müller, H. (2003). Evaluating the Fit Structural Equation Models: Tests of Significance and Descriptive Goodness-of-Fit Measures. Methods of Psychological Research Online, 8, 23-73.

Shepherdson, K. V. (1984). The Meaning of Work and Employment: Psychological Research and Psychologists' Values. Australian Psychologist, 19, 311-320.

https://doi.org/10.1080/00050068408255437

Smith, A. (1991). Recherches sur la nature et les causes de la richesse des nations. Paris: GF.

Spreitzer, G. (1995). Psychological Empowerment in the Work Place: Dimensions, Measurement, and Validation. Academy of Management Journal, 38, 1442-1465.

Spreitzer, G. M., Kizilos, M. A., \&Nason, S. W. (1997). A Dimensional Analysis of the Relationship between Psychological Empowerment and Effectiveness, Satisfaction, and Strain. Journal of Management, 23, 679-704.

Steger, M. F., Dik, B. J., \& Duffy, R. D. (2012). Measuring Meaningful Work: The Work and Meaning Inventory (MWI). Journal of Career Assessment, 00, 1-16.

Super, D. E., \& Šverko, B. (1995). Life Roles, Values, and Careers. International Findings of the Work Importance Study. San Francisco, CA: Jossey-Bass.

Wrzesniewski, A., Dutton, J. E., \& Debebe, G. (2003). Interpersonal Sensemaking and the Meaning of Work. Research in Organizational Behavior, 25, 93-135. https://doi.org/10.1016/S0191-3085(03)25003-6

Yalom, I. D. (1980). Existential Psychotherapy. New York, NY: Basic Books. 